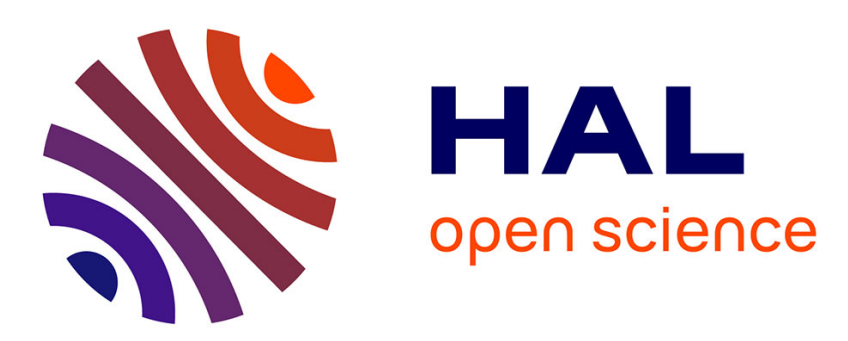

\title{
Sustainable nitrogen-doped carbonaceous materials from biomass derivatives.
}

\author{
L. Zhao, Niki Baccile, S. Gross, Y. Zhang, W. Wei, Y. Sun, M. Antonietti, \\ M.-M. Titirici
}

\section{- To cite this version:}

L. Zhao, Niki Baccile, S. Gross, Y. Zhang, W. Wei, et al.. Sustainable nitrogen-doped carbonaceous materials from biomass derivatives.. Carbon, 2010, 48 (13), pp.3778-3787. 10.1016/j.carbon.2010.06.040 . hal-00522995

\section{HAL Id: hal-00522995 https://hal.science/hal-00522995}

Submitted on 3 Feb 2017

HAL is a multi-disciplinary open access archive for the deposit and dissemination of scientific research documents, whether they are published or not. The documents may come from teaching and research institutions in France or abroad, or from public or private research centers.
L'archive ouverte pluridisciplinaire HAL, est destinée au dépôt et à la diffusion de documents scientifiques de niveau recherche, publiés ou non, émanant des établissements d'enseignement et de recherche français ou étrangers, des laboratoires publics ou privés. 
IMPORTANT NOTE : Please be aware that slight modifications occurring after Proof correction may occur between this version of the manuscript and the version on the Publisher's website

\title{
Sustainable Nitrogen-Doped Carbonaceous
}

\section{Materials from Biomass Derivatives}

\author{
Li Zhao $^{[1,2,5]}$, Niki Baccile ${ }^{[3]}$, Silvia Gross ${ }^{[4]}$, Yuanjian Zhang $^{[1]}$, WeiWei ${ }^{[2]}$, Yuhan \\ Sun $^{[2]}$, Markus Antonietti ${ }^{[1]}$, and Maria-Magdalena Titirici ${ }^{*}[1]$
}

1. Max-Planck Institute for Colloids and Interfaces, Am Mühlenberg 1, 14476 PotsdamGolm, Germany.

2. Institute of Coal Chemistry, Chinese Academy of Sciences, 030001 Taiyuan, China

3. Laboratoire de Chimie de la Matière Condensée de Paris, CNRS Collège de France, 11 Place Marcelin Berthelot, 75005 Paris, France

4. ISTM-CNR, Dipartimento di Scienze Chimiche and INSTM, University of Padova, Via Marzolo 1, 35131 Padova, Italy

5. Graduate University of the Chinese Academy of Sciences, 100039 Beijing, China 
* Corresponding Author. Maria-Magdalena Titirici Fax: (+) 49 (0)331 567 9502,

E-mail: magdalena.titirici@mpikg.mpg.de,

\begin{abstract}
:
We report here on the production of nitrogen doped carbon using the hydrothermal carbonization process of nitrogen containing carbohydrates under mild carbonization temperatures. The resulting materials contain significant amounts of nitrogen in their composition and display a high degree of aromatisation. The nitrogen contents are also maintained after further calcination at higher temperatures. All the resulting materials have been characterized using X-Ray Photoelectron Spectroscopy (XPS), solid state ${ }^{15} \mathrm{~N}$ and ${ }^{13} \mathrm{C}-\mathrm{NMR}$, elemental chemical analysis, nitrogen adsorption, Scanning (SEM) and Transmission Electron Microscopies (TEM). Finally, the nitrogen-doped materials proved to possess superior electronic conductivity to their nitrogen free counterparts.
\end{abstract}

\title{
1. Introduction
}

Carbon materials have found a large number of applications in different domains ranging from environmental science [1-3], to drug delivery [4-6] and energy storage [7], according to their structural, morphological and chemical properties [8]. Nevertheless, for some specific applications, functionalization [9-13] is required.

The properties of carbon materials depend to a large extent on the raw material, surface structure and porosity, but also heteroatoms built into their structure exert large effects on physicochemical properties of carbons. Recently, nitrogen-containing carbons attracted particular interest due to their improved performance in applications such as 
$\mathrm{CO}_{2}$ sequestration [14], removals of contaminants from gas and liquid phases [15], environmental protection [16], catalysts and catalysts supports [17], or in electrochemistry as supercapacitors [13, 18], cells and batteries [19].

The methods for the production of such materials rely normally on very harsh and multistep processes, which involve high temperature production of carbon materials [20] followed by introduction of nitrogen into the structure using ammonia, amines or urea [21, 22]. Nitrogen-containing carbons have been also more readily prepared using precursors like acetonitrile, pyrrole or polyacrylonitrile [23, 24]. However, these precursors are less sustainable and available, as compared with carbohydrates or other The problem of sustainable synthesis of nanostructures carbon materials was recently revisited and implemented by several research teams [25-31], where hydrothermal treatment of biomass in water under relatively mild conditions and, in some cases, in presence of additives like metal salts yielded bulk, mesoporous, or nanostructured carbon materials [32-46]. Although this technique was already known since 1913, [47] the need of exploring cheap and sustainable ways to obtain chemicals [48] and carbons from raw materials other than crude oil or natural gas lead to a re-exploration of this field. In addition, the implementation of a low-cost pathway to recycle byproducts of farmed biomass would additionally represent a way to sequester significant amounts of $\mathrm{CO}_{2}$ [27], and at the same time a material benefit would also be created.

Here we present a green and sustainable alternative to produce nitrogen rich carbonaceous materials which is based on the hydrothermal carbonization of nitrogencontaining carbohydrates such as chitosan or glucosamine. 


\section{Experimental Part}

\subsection{Materials and Synthesis}

All the chemicals are purchased from Sigma-Aldrich and used without further purification. Chitosan (medium molecular weight) and $\mathrm{D}(+)$-glucosamine hydrochloride (>99.0\%, HPLC) are the chosen biomass-derived nitrogen-containing carbohydrates . Nitrogen-doped carbons are synthesized as follows: 2 g carbohydrate and 18g deionized water were mixed together, then the mixture was sealed into a glass vial inside a PTFE inlets autoclave followed by hydrothermal treatment at $180{ }^{\circ} \mathrm{C}$ overnight. After the reaction, the autoclave was cooled down in a cold water bath, then the obtained black solid powder was filtered and washed with distilled water for several times. Finally, the materials were placed into a vacuum oven at $80{ }^{\circ} \mathrm{C}$ overnight for drying. The hydrothermal nitrogen-containing carbons were named as HC-Chitosan (HC-CH) and HC-Glucosamine (HC-GA). Afterwards, in order to improve the level of structural order, further high temperature treatment was performed in an oven under $\mathrm{N}_{2}$ flow at three different temperatures. The calcined samples are referred to HC-CH-750 and HC-GA750 (where $750{ }^{\circ} \mathrm{C}$ in the temperature for further calcination under a $\mathrm{N}_{2}$ stream). To compare, non-nitrogen containing carbons from $\mathrm{D}(+)$-glucose were synthesized the same way as nitrogen doped carbon. These sample were denominated as HC-Glucose (HC-G), and HC-G-750 Isotopic enrichment for sold state ${ }^{15} \mathrm{~N}$ NMR was accomplished using 1 wt $\%$ of ${ }^{15} \mathrm{~N}$-labelled glucosamine (from CortecNet). 


\subsection{Characterization methods}

The products were characterized by elemental analysis (EA) using a Vario El elemental analyzer. X-ray Diffraction (XRD) patterns were recorded in reflection mode (CuKa radiation) on a Bruker D8 diffractometer oven the $2 \theta$ range of 2-80 ${ }^{\circ}$. Scanning Electron Microscopy (SEM) images were acquired on a LEO 1550/LEO GmbH Oberkochen provided with an Everhard Thornley secondary electron and In-lens detectors. Transmission Electron Microscopy (TEM) was performed on a Zeiss EM 912 Instrument equipped with CCD camera and a filament of LaB6 under a $120 \mathrm{kV}$ tension (Carl Zeiss, Oberkochen, Germany). Nitrogen adsorption and desorption isotherms were measured at 77 K with a Quadrachrome Adsorption Instrument. The Brunaer-Emmett-Teller (BET) and DFT methods were used for the surface area determination and pore size distribution calculation. Conductivity measurements were performed by I-V method with a Gamry Ref 600 Potentiostat/Galvanostat/ZRA.

Surface charge analysis-- Zeta Potential measurements were realized on a Malvern Nano ZS instrument. Carbon powders were dispersed and stirred in $0.03 \mathrm{M} \mathrm{NaCl}$ solution at different $\mathrm{pH}$ values $(0.03 \mathrm{M} \mathrm{HCl}$ and $\mathrm{NaOH}$ were used to adjust $\mathrm{pH}$ values) for two days at $25^{\circ} \mathrm{C}$ to reach equilibrium. Due to the heterogeous nature of the samples, in order to avoid immediate pollution of the electrodes, all solutions were filtered by PTFE $5 \mu \mathrm{m}$ disposable filters. Disposable clear zeta cells (DTS1060c) were used to determine the zeta potential. Gas Chromatography (GC) was coupled to Mass Spectroscopy (MS) to separate and identify the main molecular species by mean of the NIST database included 
in the spectrometer software package. The instrument used is an Agilent Technologies $(\mathrm{GC}=6890 \mathrm{~N} ; \mathrm{MS}=5975)$ apparatus

The composition of the powder was investigated by XPS. XPS spectra were run on a Perkin-Elmer 5600ci spectrometer using standard $\mathrm{Al}$ radiation (1486.6 eV) working at $350 \mathrm{~W}$. The working pressure was $<5 \cdot 10^{-8} \mathrm{~Pa}$. The spectrometer was calibrated by assuming the binding energy (BE) of the $\mathrm{Au} 4 \mathrm{f}_{7 / 2}$ line at $83.9 \mathrm{eV}$ with respect to the Fermi level. The standard deviation for the $\mathrm{BE}$ values was $0.15 \mathrm{eV}$. The reported $\mathrm{BE}$ were corrected for the charging effects, assigning, in the outer layers where contamination carbon is still present, to the C1s line of carbon the $\mathrm{BE}$ value of $284.6 \mathrm{eV}[49,50]$. Survey scans (187.85 pass energy, $1 \mathrm{eV} / \mathrm{step}, 25 \mathrm{~ms}$ per step) were obtained in the $0-1300$ eV range. Detailed scans (58.7 eV pass energy, $0.1 \mathrm{eV} / \mathrm{step}, 100-150 \mathrm{~ms}$ per step) were recorded for the O1s, C1s, N1s regions. The atomic composition, after a Shirley type background subtraction [51] was evaluated using sensivity factors supplied by PerkinElmer [50]. Samples were introduced directly, by a fast entry lock system, into the XPS analytical chamber. The assignments of the peaks was carried out by using the values reported in the [50], in the NIST XPS Database [52] and in the references reported in the text.

${ }^{13} \mathrm{C}$ and ${ }^{15} \mathrm{~N}$ solid-state MAS NMR experiments have been acquired on a Bruker Avance III $300 \mathrm{MHz}(7.0 \mathrm{~T}), 400 \mathrm{MHz}(9.4 \mathrm{~T}), 500 \mathrm{MHz}(11.7 \mathrm{~T})$ and $700 \mathrm{MHz}(16.4 \mathrm{~T})$ spectrometers. All ${ }^{13} \mathrm{C}$ spectra have been acquired on the $7.0 \mathrm{~T}$ and $9.4 \mathrm{~T}$ spectrometers with a $4 \mathrm{~mm}$ zirconia rotor as sample holder spinning at MAS rate $v_{\mathrm{MAS}}=14 \mathrm{kHz}$. The chemical shift reference for ${ }^{13} \mathrm{C}$ was tetramethylsilane (TMS; $\delta=0 \mathrm{ppm}$ ) while the 
reported ${ }^{15} \mathrm{~N}$ chemical shifts are referenced to labeled glycine at $-348 \mathrm{ppm}$ on the nitromethane scale $\left(\mathrm{CH}_{3} \mathrm{NO}_{2}\right.$ at zero $\left.\mathrm{ppm}\right)$.

${ }^{13} \mathrm{C}$ spectra were all recorded under Cross-Polarization (CP) conditions (cross polarization time is $3 \mathrm{~s}$ ), reycle delay is $3 \mathrm{~s}$ and TPPM decoupling scheme is applied during signal acquisition. Number of transient is 1200 (HC-CH, HC-CH-T, HC-GA,), 2400 (HC-GA-T), 65 (pure GA), 64 (pure CH). Proton nutation $\left(90^{\circ}\right)$ frequencies were $5.40 \mu \mathrm{s}$ and $2.32 \mu \mathrm{s}$, respectively, on the $9.4 \mathrm{~T}$ and $7.0 \mathrm{~T}$ spectrometers.

One pulse ${ }^{15} \mathrm{~N}$ spectrum was acquired on the $11.7 \mathrm{~T}$ spectrometer with a $7 \mathrm{~mm}$ rotor $\left(v_{\mathrm{MAS}}=5 \mathrm{kHz}\right)$ and an antiring pulse programme (ARING) with a $90^{\circ}$ pulse angle. ${ }^{15} \mathrm{~N}$ nutation frequencies are $9.50 \mu \mathrm{s}\left(90^{\circ}\right)$ and $4.25 \mu \mathrm{s}\left(45^{\circ}\right)$ with respective recycle delays of 30 and 60 s. Number of transients is 9339 (recycle delay= 30 s) and 15000 (recycle delay= $60 \mathrm{~s}) .{ }^{15} \mathrm{~N}$ CP-MAS was performed on the $16.4 \mathrm{~T}$ spectrometer with a $3.2 \mathrm{~mm}$ rotor $\left(v_{\mathrm{MAS}}=22 \mathrm{kHz}\right), 3.47 \mu \mathrm{s} 90^{\circ}$ proton pulse, number of transient is 50971, recycle delay is 3s and spinal-64 decoupling pulse scheme is applied during signal acquisition.

\section{Results and Discussion}

\subsection{Morphology and Composition}

Hydrothermal carbonization of glucose and other carbohydrates has been previously described [29], leading to carbonaceous materials [31] with applications in fields such as catalysis [53], electrochemistry [54, 55] or adsorption [56]. This approach is extended 
here to the production of nitrogen doped carbon materials with chitosan (sample code HC-CH) or glucosamine (sample code HC-GA) as starting products. As-synthesized and further calcined $\left(T=750^{\circ} \mathrm{C}\right)$ nitrogen containing samples were compared with the nitrogen-free ones, as discussed below.

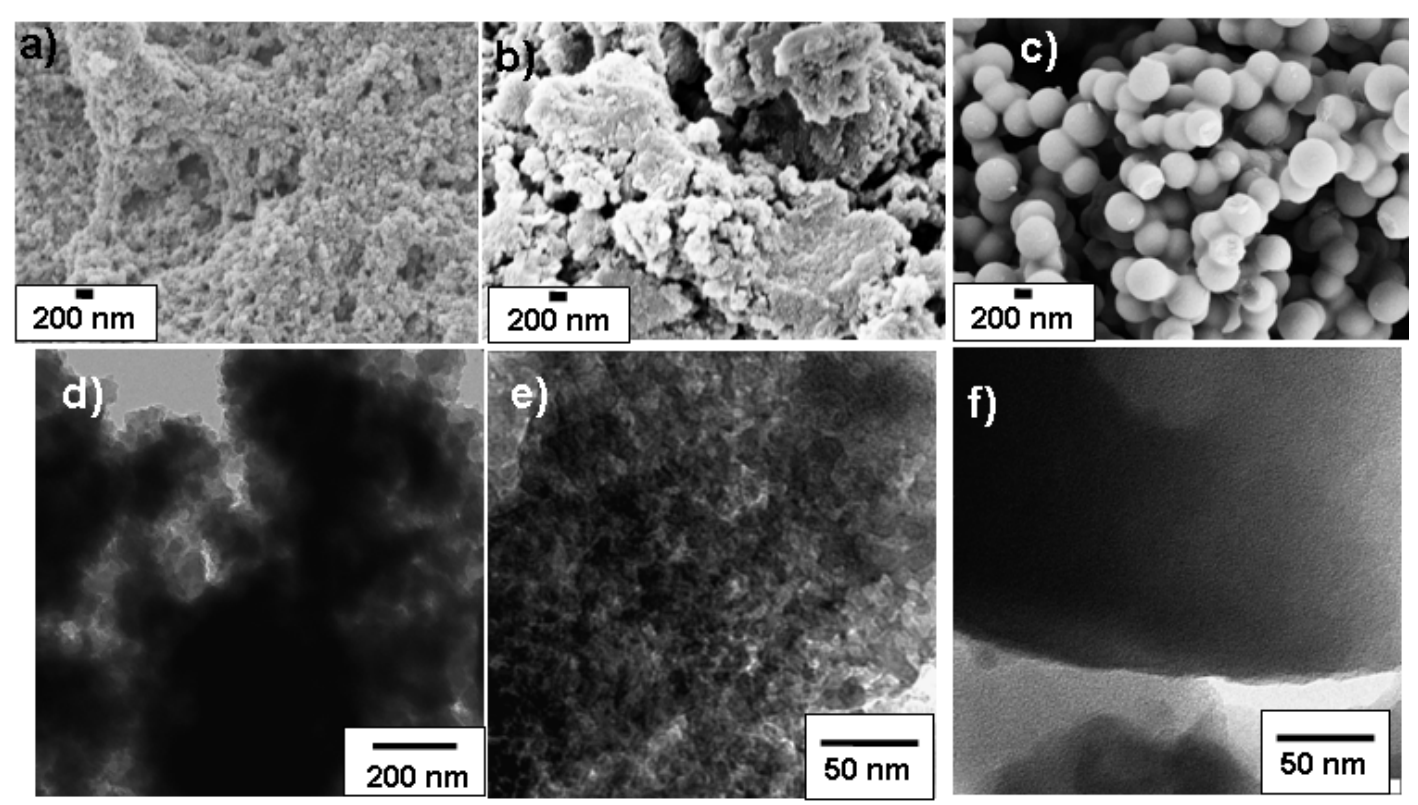

Fig. 1 - Scanning and transmission electron micrographs of the nitrogen doped carbons obtained upon hydrothermal carbonization of a,d) chitosan (HC-CH); b,e) glucosamine (HC-GA) 


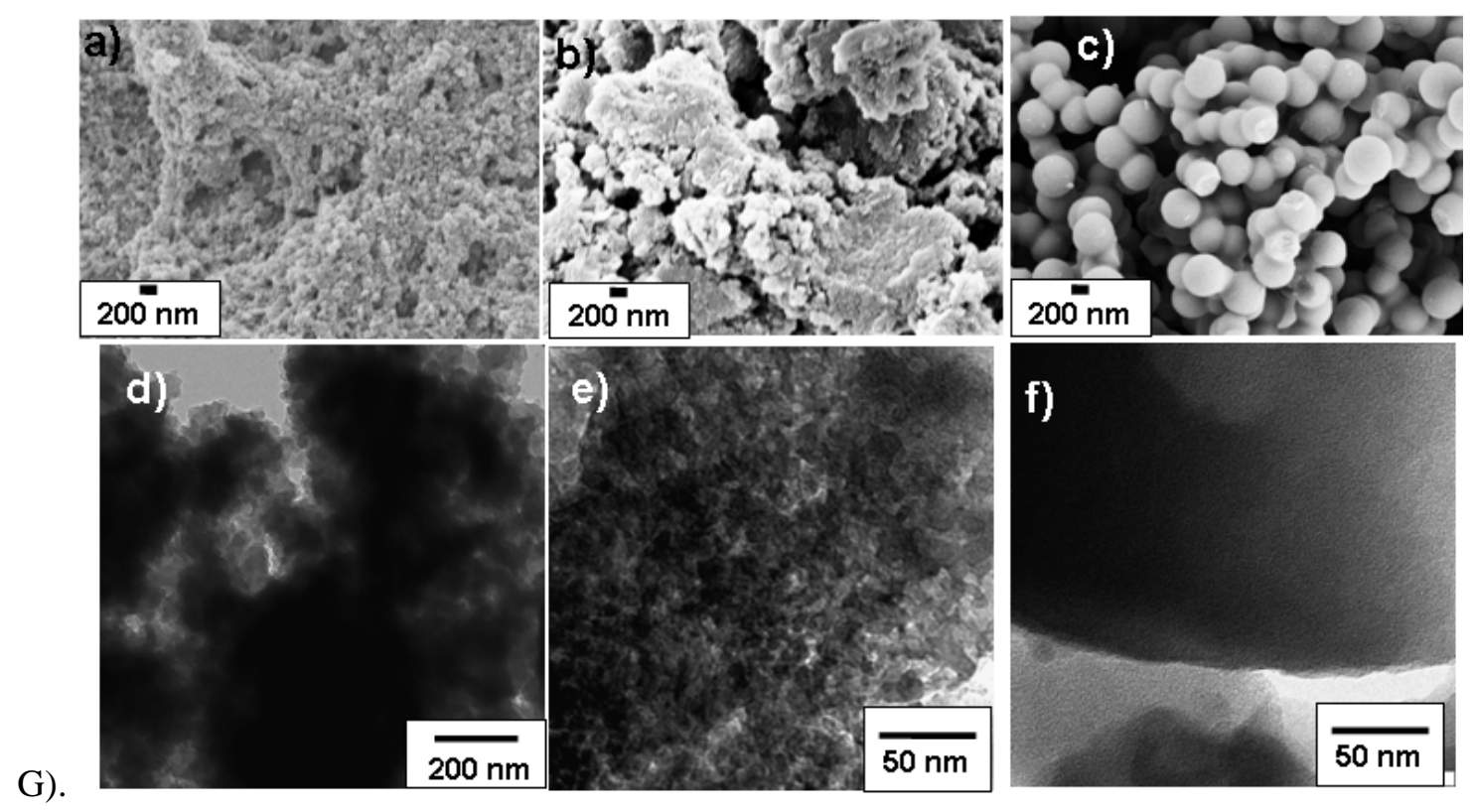

Fig. 1 shows the morphology of some hydrothermally carbonized samples. It is observed that the morphology of nitrogen containing samples is very different from the reference case of pure glucose, where hard spherical particles of $~ 400-500 \mathrm{~nm}$ diameter (SEM, Fig 1c) without inner texture (TEM, Fig 1f) are obtained [39]. In the case of chitosan no spherical particles but a continuous network of small intercalated spheres are found, displaying a monolithic structure with an interstitial macroporosity. This can be also observed from the TEM picture in Fig. 1d which shows some intercalated, irregularly shaped spheres with a diameter of about $50 \mathrm{~nm}$. Similarly, upon hydrothermal carbonization of glucosamine (Fig 1 b), a compact network formed of agglomerated smaller particles has been obtained. This is clearer when looking at the TEM micrographs (Fig.1e) which reveal again such morphology with interstitial porosity. The morphology of the samples does not change after further heat treatment. Some electron micrographs 
of the samples treated at higher temperatures are shown in Fig. S 2-supporting information, while the pure precursors, before any heat treatment, are shown in Fig. S 1

Nitrogen adsorption-desorption experiments isotherms (Fig. S 3 in supp. mater.) for nitrogen-containing HC show that the amount of adsorbed gas is very low (BET specific surface areas are lower than $10 \mathrm{~m}^{2} / \mathrm{g}$ ), and no specific porosity is actually detected. Isotherms show the typical behaviour of interparticle adsorption, suggesting that the microstructure of the material is formed of aggregated particles, in complete agreement with TEM analysis. Lack of developed porosity is generally associated with these materials[57] some exceptions exist for few specific cases, in which a more developed porosity can be achieved in the absence of an external porogen by forming monoliths from starch [33] or by reducing to the nanoscale the size of the aggregated particles[58]. Upon further carbonization some more micropores are developing, and there is a slight increase in the surface areas up to $\sim 30-50 \mathrm{~m}^{2} / \mathrm{g}$ in all materials due to an increase in microporosity.

Some interesting results come from the elemental analysis of pure and carbonized samples (Table 1). It is found that, after hydrothermal carbonization, the chitosan-derived (HC-CH) material has a carbon content of 59 w\%, lower than the one obtained for HCGA and HC (about 65 w\%). Glucosamine and glucose-derived carbons contain instead about $65 \mathrm{w} \% \mathrm{C}$ (Table 1). The amount of nitrogen is as high as $9 \mathrm{w} \%$ in HC-CH sample and $\sim 6.8 \mathrm{w} \%$ in HC-GA sample. Upon hydrothermal carbonization the carbon content for all the samples obviously increases, which is mainly due to the loss of oxygen and hydrogen in the dehydration process of the saccharides, while the amount of nitrogen is 
actually maintained constant, thus evidencing that no specific mechanism leading to the elimination of nitrogen takes place. This is interesting as it implies that nitrogen is stored in stable bonds; volatile aminated compounds, if produced, react further with the carbonaceous scaffold, as previously reported [59-61]. After further high temperature carbonization, the carbon content increases up to $89 \%$, as expected, while the nitrogen content stays virtually constant (Table 1). This suggests that indeed nitrogen is incorporated within the carbon matrix upon hydrothermal carbonization and that, upon further heat treatment, it can actually be incorporated in the graphitization process of the carbon structure.

Table 1 -Weight percentages of the carbon-based materials as obtained by elemental analysis and XPS.

\begin{tabular}{|c|c|c|c|c|c|c|}
\hline Material & $\% \mathrm{C}$ & $\% \mathrm{~N}$ & $\mathrm{C} / \mathrm{N}$ & $\% \mathrm{C}$ & $\% \mathrm{~N}$ & $\mathrm{C} / \mathrm{N}$ \\
\hline & \multicolumn{3}{|c|}{ From chemical analysis } & \multicolumn{3}{|c|}{ From XPS } \\
\hline P-Glu & 40.0 & 0 & - & & & \\
\hline $\mathrm{P}-\mathrm{CH}$ & 32.8 & 9.4 & 3.5 & & & \\
\hline P-GA & 33.4 & 6.5 & 5.1 & & & \\
\hline HC-G & 66.6 & & & & & \\
\hline HC-G-750 & 89.6 & & & & & \\
\hline $\mathrm{HC}-\mathrm{CH}$ & 56.2 & 8.9 & 6.3 & 72.5 & 5.2 & 13.9 \\
\hline HC-CH-750 & 79.2 & 9.1 & 8.8 & 87.7 & 7.7 & 11.4 \\
\hline HC-GA & 66.6 & 6.7 & 9.9 & 79.9 & 5.6 & 14.3 \\
\hline HC-GA-750 & 81.6 & 6.6 & 12.4 & 90.5 & 6.3 & 14.4 \\
\hline
\end{tabular}




\subsection{Bulk analysis}

Solid state NMR revealed to be a powerful technique to study the structure of hydrothermal carbons, which was mainly resolved as a 3D cross-linked network of furan rings. Here, ${ }^{13} \mathrm{C}$ and ${ }^{15} \mathrm{~N}$ NMR are used to characterize the structure of amino-derived carbons both after hydrothermally treatment and after further calcination at $750{ }^{\circ} \mathrm{C}$. Unfortunately, the low natural isotopic abundance of ${ }^{15} \mathrm{~N}(0.32 \%)$ and the lack of a (affordable) ${ }^{15} \mathrm{~N}$ source prevents us from performing ${ }^{15} \mathrm{~N}$ NMR experiments with good signal-to-noise ratios. ${ }^{15} \mathrm{~N}$ CP MAS experiments at natural abundance $(0.36 \%)$ did not provide any signal in a reasonable amount of time (60h), and for this reason, we were forced to apply weak isotopic enrichment using $1 \mathrm{w} \%$ of N15-labeled glucosamine. Onepulse experiments are much more time-consuming but have the advantage of providing a full insight of all nitrogen species while CP experiments are time-saving but only provide information on nitrogen atoms with a nearby protonated environment. According to both one pulse and CP experiments, two distinct nitrogen families of comparable amount exist in the HC-GA sample. The main peak at -243 ppm (Fig. 2) indicates the existence of protonated C-NH-C groups, either in the pyrrole-like or amide forms [63, 64]. Interestingly, the presence of free amino groups (-300 ppm $<\delta<-400 \mathrm{ppm}$ ) derived from glucosamine seems to be highly reduced or even disappeared, as suggested by the arguable low intensity peak at $-350 \mathrm{ppm}$. Given the low signal-to-noise ratio, one-pulse experiments do not provide any quantitative answer; nevertheless, one can safely state that primary amines have massively reacted. Fig. 2 shows two one-pulse experiments which have been acquired at two different values of recycling delay, $\mathrm{RD}=30 \mathrm{~s}$ and $60 \mathrm{~s}$. With respect to CP-MAS, the one pulse experiment at $\mathrm{RD}=30$ s (solid grey line) shows 
the presence of a signal in the $200 \mathrm{ppm}$ region, whose intensity is comparable with the signal at $243 \mathrm{ppm}$. The $200 \mathrm{ppm}$ signal indicates the presence of additional de-protonated amide groups inside the carbonaceous scaffold. Moreover, the same one-pulse experiment at longer recycling delays $(\mathrm{RD}=60$ s, black dotted line) shows a broad hump between -78 and $-200 \mathrm{ppm}[63,64]$; this is the fingerprint of conjugated, pyridine-like, C$\mathrm{N}=\mathrm{C}$ aromatic networks. Due to the probably very long spin-network relaxation times of nitrogen in all these chemical species, longer RD should be used to recover their full signal; which was however result in extremely long, difficult to realize, N15 experiments.

Several literature reports exist on the degradation mechanisms of GA in water at high temperatures [59-61], and in most cases, they agree on the fact that glucosamine dehydrates into hydroxymethyl furfural (HMF), which is also the major transformation product of glucose dehydration under the same conditions [65-68], and release of ammonia in solution. Then, $\mathrm{NH}_{3}$ readily reacts with $\mathrm{HMF}$ to form several type of $\mathrm{N}$ containing molecules [60, 61]. In general, pyrrole-like [60] or pyridine and pyrazine [60, 61] compounds are described but the possibility to form amide bonds exist [59]. Interestingly, in many cases, the furanic moiety is kept throughout the process, and it is substituted by nitrogen at different positions. The ${ }^{15} \mathrm{~N}$ experiments presented above on the HC-GA sample indicate a large amount of protonated, substituted pyrrole-like molecules or amide bonds. Aromatic $\mathrm{C}-\mathrm{N}=\mathrm{C}$ compounds, even if their identification is a difficult task, are also formed. We believe that several mechanisms may take place to transform glucosamine into N-carbon. The preferred mechanism of formation of HC-GA should pass through the production of ammonia and its reaction with HMF or similar furanic compounds. Considered the lower amount of aromatic amines, the mechanism leading to 
aromatic amines (e.g., dimerization of two glucosamine moieties, as proposed by Jun et al. [61]) does not abundantly take place here. ${ }^{13} \mathrm{C}$ NMR data shown below suggest a strong aromaticity for HC-GA with respect to HC-G, supporting the idea that aromatic amines are distributed throughout the material.

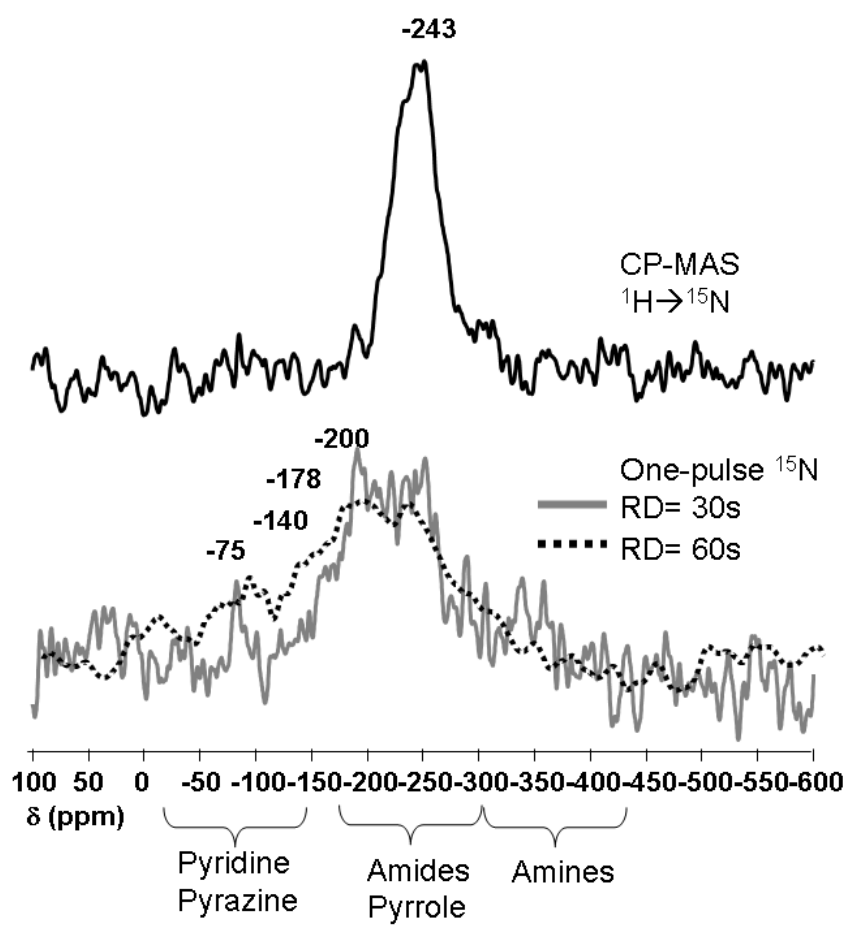

Fig. $2-{ }^{15} \mathrm{~N}$ CP-MAS and one-pulse experiments performed on the HC-GA sample. N15 enrichment was necessary. $\mathrm{RD}=$ Recycle Delay.

${ }^{13} \mathrm{C}$ CP MAS NMR was performed on all amino-derived samples, and the results are as shown in Fig. 3. As a matter of comparison, we report the typical spectrum of a pure hydrothermal carbon from glucose (HC-G) in Fig. 3-B. A crude attribution can be done as follows: $\delta=10-50 \mathrm{ppm}$ : aliphatic $\mathrm{CH}_{\mathrm{x}}$ groups; $\delta=100-150$ : aromatic range, mainly dominated by the furanic ring (sp2 $\beta$-carbons resonate between 100-130 ppm while oxygenated $\alpha$-carbons resonate between $130-150 \mathrm{ppm}$ ). Only less than $6 \%$ of total 
carbons are involved in a pure graphite-like structure (peak at $130 \mathrm{ppm}$ ). Peaks at 175 and 210 ppm belong to the different carbonyl groups. When thermal treatment at $750{ }^{\circ} \mathrm{C}$ is applied, the corresponding spectrum (A) shows a single main peak between 125-130 ppm, with a clear loss of all aliphatic and carbonyl groups and the furanic doublet. This behaviour is rather typical for a strong graphitization of the material.
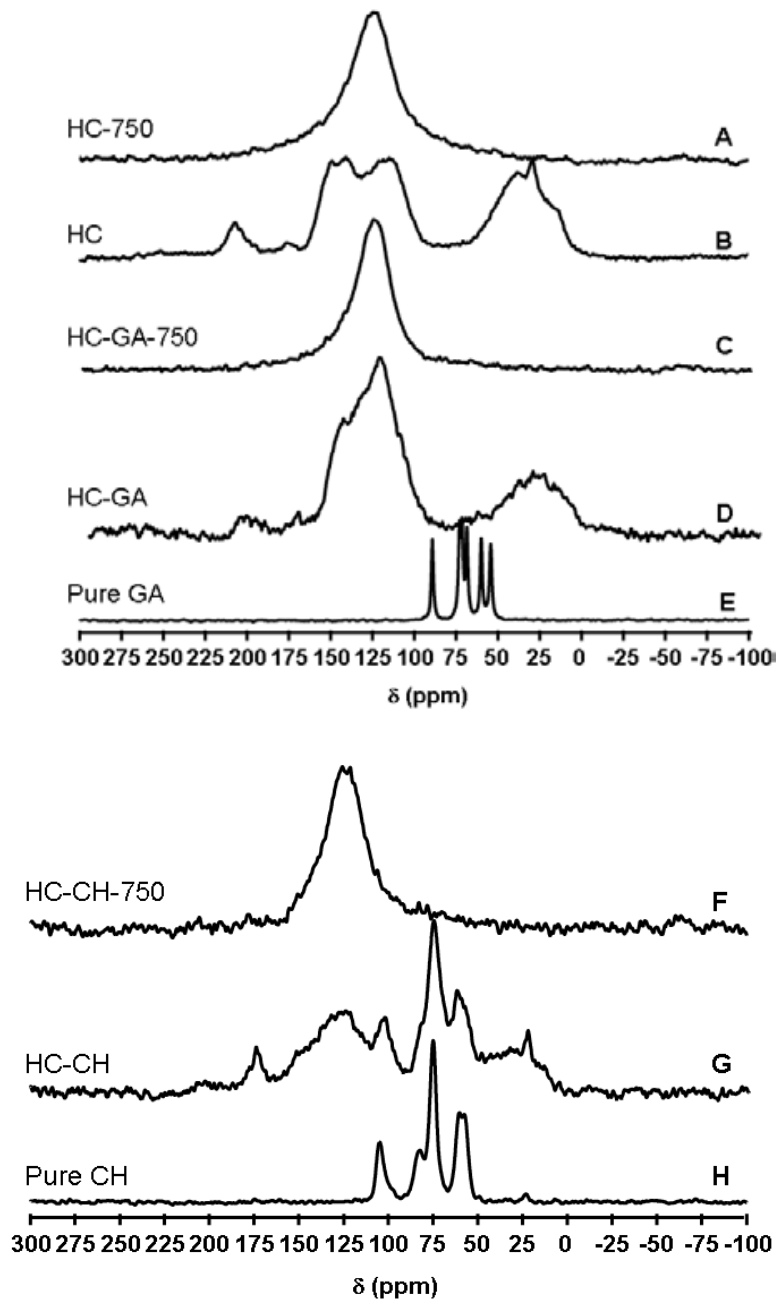

Fig. $3-{ }^{13} \mathrm{C}$ CP-MAS experiments performed on the pure precursors, the hydrothermally treated and carbonized $\left(750^{\circ} \mathrm{C}\right)$ samples.

Some changes in the ${ }^{13} \mathrm{C}$ CP MAS behaviour are found when using gluosamine as the 
direct nitrogen-containing source for HC, (HC-GA, Fig. 3-D). If aliphatic and carbonyl regions do not show major changes, the amount of $\mathrm{COOH}$ groups at $175 \mathrm{ppm}$ seem to have relatively decreased or, at least, the peak seem to be broader. This behaviour is indicative for the reaction of the carboxylic species. The aromatic region (100-150 ppm), on the contrary, shows a single, main contribution between 125-130 ppm, suggesting occurrence of the graphitization already throughout the hydrothermal treatment. Secondary peaks due to furanes at 150 and $110 \mathrm{ppm}$ can also be identified. These data show that the structure of the GA-derived carbons is far from being similar to the one of the glucose-derived hydrothermal carbons, with HC-GA having strong N-heterocyclic aromaticity while having only a weak contribution from furanic moieties.

Calcination at $750{ }^{\circ} \mathrm{C}$ (sample HC-GA-750) provides the general effect found for all hydrothermal carbons: loss of all aliphatic and carbonyl peaks while intensification of the peak between 125-130 ppm suggests a wide graphitization of the carbon samples. Residual presence of a shoulder peak in the $150 \mathrm{ppm}$ area is still sign of oxygenated and/or aminated sp2 carbons. When comparing the ${ }^{13} \mathrm{C}$ NMR spectra of the glucosaminebased HC-GA materials (Fig. 3 spectrum D) with a pure glucosamine sample (Fig. 3 spectra E), it is quite evident that almost the whole amount of the amino-sugar has reacted, as its peaks between 50 and $75 \mathrm{ppm}$ have disappeared. On the contrary, the chitosan-derived HC materials (figure 5, spectrum G) still possesses strong signals.

Therefore, the ${ }^{13} \mathrm{C}$ solid state CPMAS NMR analysis shows that the hydrothermal treatment of aminated sugars enhances the carbonization process towards more aromatic carbons with extended graphitic domains already throughout hydrothermal treatment at 
$180^{\circ} \mathrm{C}$, while the differently aminated chitosan results in lower carbonizaiton efficiencies along the traditional reaction scheme. These data also nicely mirror the elemental analysis results.

\subsection{Surface analysis}

Surface properties of the carbonaceous materials were characterized with XPS and $\zeta$ potential measurements. XPS analysis was performed on the pure starting precursors, on the hydrothermally treated samples and on the carbonized samples. Detailed spectra were collected for the three ??? regions of interest (N1s in Fig. 4 and C1s in Fig. S 4). from which the atomic percentages of the two elements could be calculated (reported in Table 1). As it can be evidenced by comparing the atomic percentage values obtained by XPS with those calculated from the weight percentages delivered by elemental analysis, the amounts of carbon detected by XPS is systematically higher that those calculated starting from the experimental weight percentages obtained by elemental analysis. Noooooo, this is brutally wrong. XPS is by no means a quantitative technique, as the spectra a folded with a so-calles exit work functions, means: you only see conducting, wave function localized parts of the sample, which are not representative. I hope Niki added this sentence, as I have hoped to have you educated differently. :-

This shows that the surface of the material is rather oxygen-poor if compared to its bulk. As we previously discussed, the core structure of hydrothermal carbon powders is mainly composed of furan rings interconnected via aliphatic bridges. Zeta-potential data, showing a negative surface charge for HC-G (see Fig. 5 below), combined to quantitative ${ }^{13} \mathrm{C}$ solid-state NMR experiments [62], displaying a low amount of $\mathrm{COOH}$ 
groups ( $<10 \%$ with respect to carbon atom), allow us to say that, most likely, the only oxygen source at the material surface is constituted by carboxylic groups. Again crude bullshit, erase...

Remarkably, atomic percentage values for nitrogen are high for all samples and, in agreement with elemental analysis, their values increase with increasing thermal treatment. On the contrary, upon heating, the discrepancy in carbon amount between chemical and XPS analysis is drastically reduced. Yes, of course, see my words above... This information, coupled to the disappearance of the carbonyl peaks with temperature as shown by ${ }^{13} \mathrm{C}$ solid state NMR experiments (Fig. 3), confirms the picture of a carboxyrich surface.

Wipe out... 

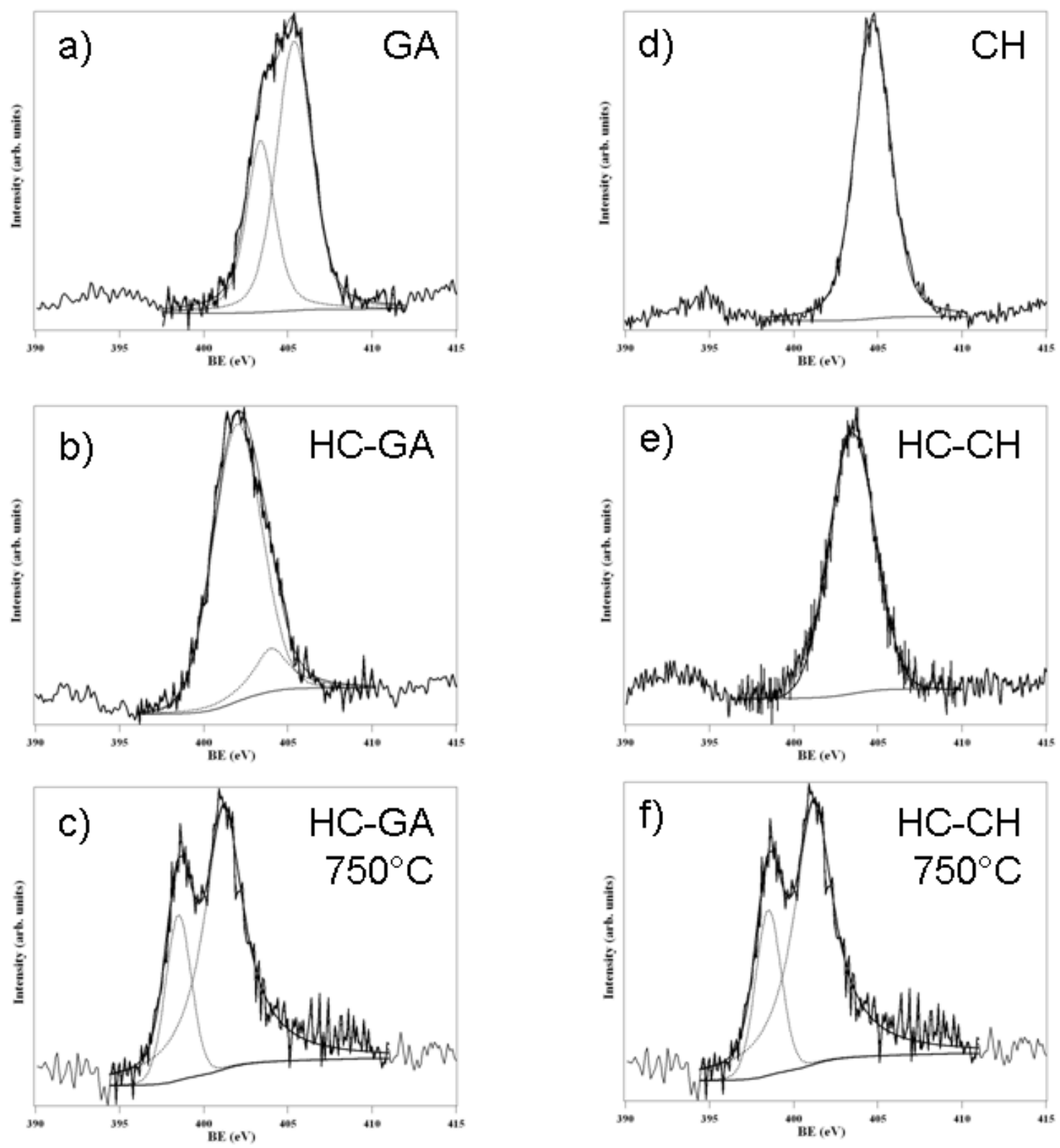

Fig. 4 - N1s signals of the pure, hydrothermally treated and calcined glucosamine (GA) and chitosan (CH) samples. The values in the abscissa are not corrected for charging effects. Refer to discussion in the text or to Table 1 for corrected values. ?? what does this mean, leftover?? 
The XPS spectra for the chitosan series are shown together with a deconvolution of the C1s and N1s peaks in Fig. S 4 and Fig. 4, respectively. The values for the binding energies together with their assessments are presented in

Table S 1 in the supplementary material. In the case of pure chitosan, according to references reported in literature[69], three different carbon components could be identified: the more intense one, at $286.1 \mathrm{eV}$, was ascribed to carbon bonded to $-\mathrm{OH}$ and/or OR groups, whereas the component at lower $\mathrm{BE}(284.6 \mathrm{eV})$ was assigned to aliphatic carbon/adventitious carbon; the one at higher BE $(287.9 \mathrm{eV})$ is attributed to CO-C moieties. After the hydrothermal carbonization, the band at $284.6 \mathrm{eV}$ corresponding to the $\mathrm{sp}^{3}$ hybridized carbon is still present meaning in this sample, as previously shown by ${ }^{13} \mathrm{C}$-solid state NMR experiments (see Fig. 3). After further carbonization at higher temperatures, major changes in the structure are visible. First of all, a decrease in oxygen content and an increase in the $\mathrm{C} / \mathrm{N}$ ratio is observed. Secondly the sample derived from chitosan treated at $750^{\circ} \mathrm{C}$ shows only a C1s component at $285.1 \mathrm{eV}$ meaning almost all the oxygenated functionalities were removed from the sample, in agreement with elemental analysis and ${ }^{13} \mathrm{C}$ solid state NMR. The same trend could be observed also in the glucosamine-derived sample. This component at $285.1 \mathrm{eV}$ corresponds to a predominantly $\mathrm{sp}^{2}$ hybridized aromatic system (reference value 284.8-285.0 eV).

Concerning the N1s peak (Fig. 4), the pure chitosan sample shows only one component which according to the binding energy value (399.3 eV) corresponds to the 
primary amine group, as expected. After hydrothermal carbonization the binding energy shifts from 399.3 to $402.1 \mathrm{eV}$, thus suggesting that the amino group has undergone a chemical reaction leading to the formation of quaternary $\mathrm{N}$ in aromatic graphene structure. [21, 71, 72] Upon even further heat treatment at higher temperature $\left(750^{\circ} \mathrm{C}\right)$, the N1s region could be fitted with two components, with very different positions with respect to the untreated samples: a more intense one at 400.5 and a less intense at 398.0 $\mathrm{eV}$, with an intensity ratio of about $4: 1$. Whereas the former component was ascribed to a tertiary $\mathrm{N}$ in aromatic graphene structure[21, 71], the second one has a value which is typical of that reported for pyridinic (aromatic) nitrogen [72].

A similar trend can be observed in the case of glucosamine precursor. The C1s spectra of the pure precursors show the presence of three components of $\mathrm{C}-\mathrm{H}$, of $\mathrm{C}-\mathrm{OH}$ and $\mathrm{C}-\mathrm{O}-$ C bonds which are also partly maintained after the hydrothermal carbonization. Clear differences between the pure precursors and the hydrothermal carbonized materials do not appear to be significant in XPS. From ${ }^{13} \mathrm{C}$ solid state NMR experiments (Fig. 3), we know that glucosamine has gone under full reaction after hydrothermal treatment; this means that the carbon species detected by XPS do not belong to the glucosamine molecule but rather to $\mathrm{CH}$ and $\mathrm{C}-\mathrm{O}-\mathrm{C}$ groups derived from the carbonization process and largely described in [62]. Well, a weak part of the discussion as these data contradict themselves. You clearly cannot write it like that, but Silvia will certainly correct.

Upon further calcination of the HC material under nitrogen, we again find only one component for the C1s corresponding to an aromatic system with only very little oxygenated functionality. 
In both chitosan- and glucosamine-based samples, upon hydrothermal treatment, although the different components of $\mathrm{C} 1 \mathrm{~s}$ can be observed, but their intensity ratios changes, and an increase of the aromatic/aliphatic part can be observed with respect to the pure precursors. As far as pure glucosamine is concerned, the N1s region contains two components, at 399.3 and $400.2 \mathrm{eV}$, corresponding to amine and to protonated amine groups (the starting product is an acidified glucosamine). In the case of HC-GA, the N1s peak shows two components at 399.3 and $401.3 \mathrm{eV}$, respectively. The former can be ascribed to pyridinic nitrogen, the latter to quaternary $\mathrm{N}$ in condensed polyaromatic structure, in agreement with what observed by NMR. Upon further carbonization at $750^{\circ} \mathrm{C}$, two components at $398.1 \mathrm{eV}$ and $400.8 \mathrm{eV}$, ascribed to amide [73] and to a ternary $\mathrm{N}$ in aromatic graphene structure, respectively, could be observed. XPS data confirm ${ }^{15} \mathrm{~N}$ NMR experiments (Fig. 2) showing that nitrogen is incorporated into the core of a more aromatized system.

What is this part good for, except repeating everything ?? If there is nothing new, just cross out, as you simple do not explain things twice in a line. I think this is a parallel leftover..

The structural study performed so far by electron microscopy, XPS and NMR suggest an altered growth under hydrothermal treatment of amino-group containing carbohydrates. We have shown that the mechanism of transformation of glucose into carbon-like materials under hydrothermal conditions involves the dehydration of glucose to hydroxymethyfurfural (HMF) in the first step, followed by the polymerization and aromatization of the latter to produce the carbonaceous material[29, 74]. In the case of 
amino containing carbohydrates, the transformation process is much more complex, as we previously discussed. In addition, Maillard-type reactions (very well known in food chemistry $[73,75]$ ) between HMF (containing an aldehyde group) and the amine may also take place and lead towards nitrogen-containing heterocycles. This scenario is also supported by the GS-MS spectra of the liquid phase obtained upon hydrothermal carbonization of chitosan and glucosamine (data not shown), which shows only small traces of HMF in comparison with pure glucose, but shows indeed nitrogen containing heterocycles which are not detected in the case of pure glucose. In addition, consumption of amine groups is also clear from CP-MAS ${ }^{15} \mathrm{~N}$ solid state NMR spectra of HC-GA (Fig. 3). And again: what is this good for. Again a summary or conclusion within the discussion. If yes, either cross out completely or move to the Conclusion

Zeta-potential experiments as a function of $\mathrm{pH}$ on aqueous dispersions of the samples (Fig. 5) can help to further characterize the nitrogen functions. The as-synthesized HC$\mathrm{CH}$ and HC-GA hydrothermal powders (Fig. 5 a) clearly show positive zeta-potentials below $\mathrm{pH} \sim 5-6$, indicating the existence of positively charged, accessible amino groups at the particle's surface with values up to $30 \mathrm{mV}$ at $\mathrm{pH}$ 2.5. These data are coherent with XPS analysis, which have showed that roughly $6 \%$ of nitrogen sites at the material surface, and ${ }^{15} \mathrm{~N}$ NMR data, which have shown the presence of protonated pyrrolic sites. On the contrary, pure hydrothermal carbon (HC) from glucose shows no positive zetapotential value in the whole examined range, as previously described [58]. Analyzing the effects of calcination on the zeta-potential (Fig. 5b), it is found that the positive character is clearly diminished by the temperature treatment. A nearby explanation in agreement 
with XPS nitrogenated functions is that the nitrogen is now incorporated into the aromatic carbon system and therefore has a much less basic in character.
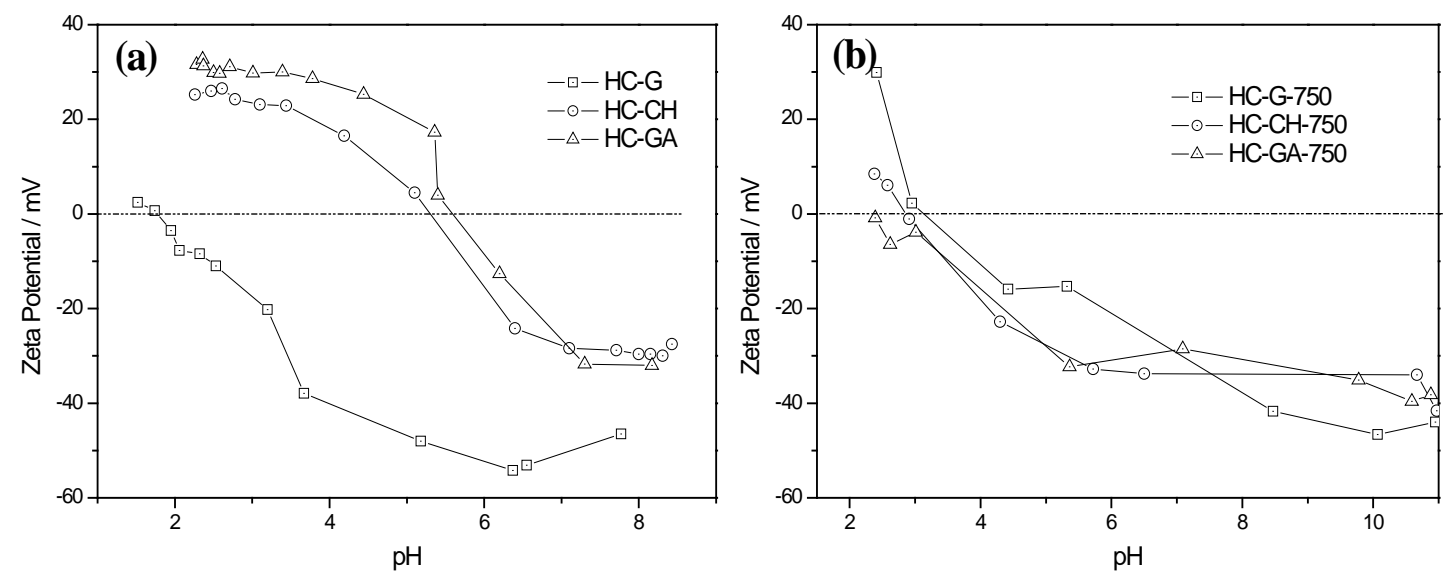

Fig. 5 - Zeta- potential experiments of (a) HC-G, HC-CH and HC-GA; (b) HC-G750, HC-CH-750 and HC-GA-750.

XRD measurements on the prepared samples show one single broad reflection for the HC-GA and HC-GA-350 while a second one at a doubled 2-theta value (arrghh, again one of those mistakes: the is not a second order reflection but the in plane organization of graphite..) Change starts to appear for samples treated at $550^{\circ} \mathrm{C}$ and above. This demonstrates that at low temperatures, the sample has an amorphous structure whose order improves towards a lamellar phase with increasing the temperature (Fig. 6). In addition, the width of the (002) and (100) reflections at, respectively, $2 \theta=24^{\circ}$ and $48^{\circ}$, typical for interlayer stacking, decreases with increasing the temperature, showing that long-range order improves. Thus, only a very broad peak at $2 \theta=25$ is found after hydrothermal carbonization, while the reflection at $45^{\circ}$ corresponding to the (100) order of graphite cannot be observed in this sample 
This is fucking wrong, and it was correct in the original version. I am sick of correcting always the same shit put back in the paper....

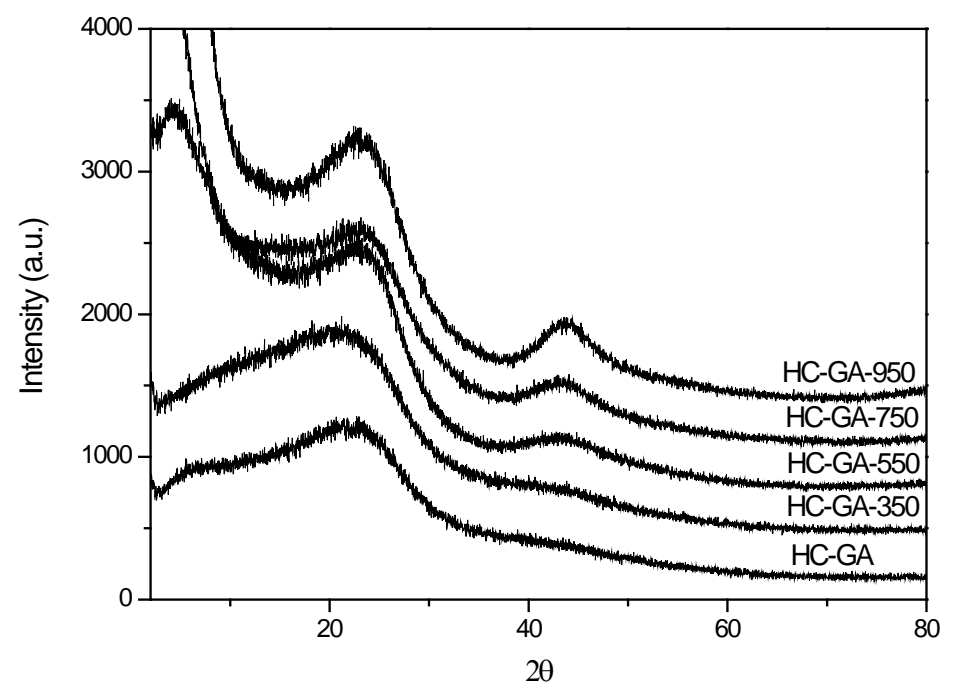

Fig. 6 - XRD profiles of the carbons obtained from glucosamine at different temperatures.

As stated above, nitrogen doped carbons are interesting materials due to their improved performance. Like other carbon nanostructures such as carbon nanotubes, hydrothermal carbon's electronic band structure was also probably significant influenced by nitrogen doping[62]. Therefore, conductivity measurements of samples after further carbonization at $750{ }^{\circ} \mathrm{C}$ were undertaken. Results shown in Table 3 that nitrogen doped hydrothermal carbon based on chitosan and glucosamine, show an improved electronic conductivity with respect to the glucose based carbon.

Table 3. Conductivities of HC-G-750, HC-CH-750 and HC-GA-750. 


\begin{tabular}{l|c|c|c}
\hline Sample & HC-G-750 & HC-CH-750 & HC-GA-750 \\
\hline Conductivity (S/m) & $80.3 \pm 10.5$ & $100.3 \pm 19.5$ & $103.7 \pm 9.7$ \\
\hline
\end{tabular}

\section{Conclusion}

We have demonstrated that it is possible to synthesize nitrogen containing carbonaceous materials by using hydrothermal treatment at $180{ }^{\circ} \mathrm{C}$ of amino containing carbohydrates. Besides being green, cheap and sustainable, this process has the advantage to introduce nitrogen dopants into the carbonaceous scaffold, which are known to be very favorable for catalysis, adsorption, or energy storage devices Various characterization methods (nitrogen adsorption-desorption, TEM, SEM, XPS, ${ }^{13} \mathrm{C}$-solid state NMR, XRD, zeta potential and elemental analysis) were used to describe the resulting carbon structures. Temperature treatments showed that all materials retain the nitrogen content almost unchanged up to $750{ }^{\circ} \mathrm{C}$. Maybe one of the most important benefit of the nitrogen dopant is the fact that we can increase spontaneous aromatization already at $180^{\circ} \mathrm{C}$ in a hydrothermal treatment

The beneficial properties were exemplified by the conductivity measurements where an increase of the direct current conductivity was found for the nitrogen containing materials

Last but not least, the whole synthetic process occurs in an energy and atom-saving fashion from cheap and sustainable resources, as employed temperatures in the first step remain below $200{ }^{\circ} \mathrm{C}$, and neither metals nor surfactants have been used to catalyze and control the reaction. 
We are presently investigating the performance of such nitrogen containing carbon materials in fields such $\mathrm{CO}_{2}$ sequestration, supercapacitors as well as catalysts. The preliminary results are very promising especially in the filed of selective $\mathrm{CO}_{2}$ sequestration showing such easy produced materials could be of major importance.

\section{References}

[1] Mauter MS, Elimelech M. Environmental applications of carbon-based nanomaterials. Environmental Science \& Technology. 2008 Aug 15;42(16):5843-59.

[2] Jia YF, Steele CJ, Hayward IP, Thomas KM. Mechanism of adsorption of gold and silver species on activated carbons. Carbon. 1998;36(9):1299-308.

[3] Huang CP, Wu MH. Removal of Chromium(Vi) from Dilute Aqueous-Solution by Activated Carbon. Water Research. 1977;11(8):673-9.

[4] Pantarotto D, Briand JP, Prato M, Bianco A. Translocation of bioactive peptides across cell membranes by carbon nanotubes. Chemical Communications. 2004 Jan 7(1):16-17. 
[5] Kam NWS, Jessop TC, Wender PA, Dai HJ. Nanotube molecular transporters: Internalization of carbon nanotube-protein conjugates into mammalian cells. Journal of the American Chemical Society. 2004 Jun 9;126(22):6850-1.

[6] Yan AH, Lau BW, Weissman BS, Kulaots I, Yang NYC, Kane AB, et al. Biocompatible, hydrophilic, supramolecular carbon nanoparticles for cell delivery. Advanced Materials. 2006 Sep 18;18(18):2373-8.

[7] Dillon AC, Jones KM, Bekkedahl TA, Kiang CH, Bethune DS, Heben MJ. Storage of hydrogen in single-walled carbon nanotubes. Nature. 1997 Mar 27;386(6623):377-9.

[8] Zakhidov AA, Baughman RH, Iqbal Z, Cui CX, Khayrullin I, Dantas SO, et al. Carbon structures with three-dimensional periodicity at optical wavelengths. Science. 1998 Oct 30;282(5390):897-901.

[9] Lin Y, Rao AM, Sadanadan B, Kenik EA, Sun YP. Functionalizing multiplewalled carbon nanotubes with aminopolymers. Journal of Physical Chemistry B. 2002 Feb 14;106(6):1294-8.

[10] Jurewicz K, Babel K, Ziolkowski A, Wachowska H, Kozlowski M. Ammoxidation of brown coals for supercapacitors. Fuel Processing Technology. 2002 Jun 20;77:191-8.

[11] Hsieh CT, Teng H. Influence of oxygen treatment on electric double-layer capacitance of activated carbon fabrics. Carbon. 2002;40(5):667-74. 
[12] Lota G, Grzyb B, Machnikowska H, Machnikowski J, Frackowiak E. Effect of nitrogen in carbon electrode on the supercapacitor performance. Chemical Physics Letters. 2005 Mar 7;404(1-3):53-8.

[13] Hulicova D, Kodama M, Hatori H. Electrochemical performance of nitrogenenriched carbons in aqueous and non-aqueous supercapacitors. Chemistry of Materials. 2006 May 2;18(9):2318-26.

[14] Plaza MG, Pevida C, Arenillas A, Rubiera F, Pis JJ. CO2 capture by adsorption with nitrogen enriched carbons. Fuel. 2007 Sep;86(14):2204-12.

[15] Stavropoulos GG, Samaras P, Sakellaropoulos GP. Effect of activated carbons modification on porosity, surface structure and phenol adsorption. Journal of Hazardous Materials. 2008 Mar 1;151(2-3):414-21.

[16] Jia YF, Xiao B, Thomas KM. Adsorption of metal ions on nitrogen surface functional groups in activated carbons. Langmuir. 2002 Jan 22;18(2):470-8.

[17] Shao YY, Sui JH, Yin GP, Gao YZ. Nitrogen-doped carbon nanostructures and their composites as catalytic materials for proton exchange membrane fuel cell. Applied Catalysis B-Environmental. 2008 Feb 21;79(1-2):89-99.

[18] Kawaguchi M, Itoh A, Yagi S, Oda H. Preparation and characterization of carbonaceous materials containing nitrogen as electrochemical capacitor. Journal of Power Sources. 2007 Oct 11;172(1):481-6. 
[19] Weydanz WJ, Way BM, van Buuren T, Dahn JR. Behavior of NitrogenSubstituted Carbon (N[sub z]C[sub 1 - z]) in Li/Li(N[sub z]C[sub 1 - z])[sub 6] Cells. Journal of The Electrochemical Society. 1994;141(4):900-7.

[20] Nxumalo EN, Nyamori VO, Coville NJ. CVD synthesis of nitrogen doped carbon nanotubes using ferrocene/aniline mixtures. Journal of Organometallic Chemistry. 2008 Aug 15;693(17):2942-8.

[21] Burg P, Fydrych P, Cagniant D, Nanse G, Bimer J, Jankowska A. The characterization of nitrogen-enriched activated carbons by IR, XPS and LSER methods. Carbon. 2002;40(9):1521-31.

[22] Huang MC, Teng HS. Nitrogen-containing carbons from phenol-formaldehyde resins and their catalytic activity in NO reduction with NH3. Carbon. 2003;41(5):951-7.

[23] Yang Z, Xia Y, Sun X, Mokaya R. Preparation and Hydrogen Storage Properties of Zeolite-Templated Carbon Materials Nanocast via Chemical Vapor Deposition:\&nbsp; Effect of the Zeolite Template and Nitrogen Doping. The Journal of Physical Chemistry B. 2006;110(37):18424-31.

[24] Hou PX, Orikasa H, Yamazaki T, Matsuoka K, Tomita A, Setoyama N, et al. Synthesis of nitrogen-containing microporous carbon with a highly ordered structure and effect of nitrogen doping on $\mathrm{H} 2 \mathrm{O}$ adsorption. Chemistry of Materials. 2005 Oct 4;17(20):5187-93. 
[25] Wang Q, Li H, Chen LQ, Huang XJ. Monodispersed hard carbon spherules with uniform nanopores. Carbon. 2001;39(14):2211-4.

[26] Wang Q, Li H, Chen LQ, Huang XJ. Novel spherical microporous carbon as anode material for Li-ion batteries. Solid State Ionics. 2002;152:43-50.

[27] Titirici MM, Thomas A, Antonietti M. Back in the black: hydrothermal carbonization of plant material as an efficient chemical process to treat the $\mathrm{CO} 2$ problem? New Journal of Chemistry. 2007;31(6):787-9.

[28] Titirici MM, Thomas A, Antonietti M. Replication and coating of silica templates by hydrothermal carbonization. Advanced Functional Materials. 2007 Apr 16;17(6):1010-8.

[29] Titirici MM, Antonietti M, Baccile N. Hydrothermal carbon from biomass: a comparison of the local structure from poly- to monosaccharides and pentoses/hexoses. Green Chemistry. 2008;10(11):1204-12.

[30] Budarin V, Clark JH, Hardy JJE, Luque R, Milkowski K, Tavener SJ, et al. Starbons: New starch-derived mesoporous carbonaceous materials with tunable properties. Angewandte Chemie-International Edition. 2006;45(23):3782-6.

[31] Titirici MM, Thomas A, Yu SH, Muller JO, Antonietti M. A direct synthesis of mesoporous carbons with bicontinuous pore morphology from crude plant material by hydrothermal carbonization. Chemistry of Materials. 2007 Aug 21;19(17):4205-12. 
[32] Budarin VL, Clark JH, Luque R, Macquarrie DJ, Koutinas A, Webb C. Tunable mesoporous materials optimised for aqueous phase esterifications. Green Chemistry. 2007;9(9):992-5.

[33] Budarin V, Luque R, Macquarrie DJ, Clark JH. Towards a bio-based industry: Benign catalytic esterifications of succinic acid in the presence of water. Chemistry-a European Journal. 2007;13(24):6914-9.

[34] White RJ, Budarin VL, Clark JH. Tuneable mesoporous materials from alpha-Dpolysaccharides. Chemsuschem. 2008;1(5):408-11.

[35] Yu SH, Cui XJ, Li LL, Li K, Yu B, Antonietti M, et al. From starch to metal/carbon hybrid nanostructures: Hydrothermal metal-catalyzed carbonization. Advanced Materials. 2004 Sep 16;16(18):1636-40.

[36] Yao C, Shin Y, Wang LQ, Windisch CF, Samuels WD, Arey BW, et al. Hydrothermal dehydration of aqueous fructose solutions in a closed system. Journal of Physical Chemistry C. 2007 Oct 25;111(42):15141-5.

[37] Cui XJ, Antonietti M, Yu SH. Structural effects of iron oxide nanoparticles and iron ions on the hydrothermal carbonization of starch and rice carbohydrates. Small. 2006 Jun;2(6):756-9.

[38] Sevilla M, Lota G, Fuertes AB. Saccharide-based graphitic carbon nanocoils as supports for PtRu nanoparticles for methanol electrooxidation. Journal of Power Sources. 2007 Sep 27;171(2):546-51. 
[39] Sun XM, Li YD. Colloidal carbon spheres and their core/shell structures with noble-metal nanoparticles. Angewandte Chemie-International Edition. 2004;43(5):597601.

[40] Sun TL, Liu HA, Song WL, Wang X, Jiang L, Li L, et al. Responsive aligned carbon nanotubes. Angewandte Chemie-International Edition. 2004;43(35):4663-6.

[41] Sun YP, Fu KF, Lin Y, Huang WJ. Functionalized carbon nanotubes: Properties and applications. Accounts of Chemical Research. 2002 Dec;35(12):1096-104.

[42] Steiner M, Qian H, Hartschuh A, Meixner AJ. Controlling nonequilibrium phonon populations in single-walled carbon nanotubes. Nano Letters. 2007;7:2239-42.

[43] Yang HX, Qian JF, Chen ZX, Ai XP, Cao YL. Multilayered nanocrystalline SnO2 hollow microspheres synthesized by chemically induced self-assembly in the hydrothermal environment. Journal of Physical Chemistry C. 2007 Sep 27;111(38):14067-71.

[44] Zhu K, Egeblad K, Christensen CH. Mesoporous carbon prepared from carbohydrate as hard template for hierarchical zeolites. European Journal of Inorganic Chemistry. 2007 Sep(25):3955-60.

[45] Hu J, Li H, Huang X. Electrochemical behavior and microstructure variation of hard carbon nano-spherules as anode material for Li-ion batteries. Solid State Ionics. 2007;178(3-4):265-71. 
[46] Titirici MM, Antonietti M, Thomas A. A generalized synthesis of metal oxide hollow spheres using a hydrothermal approach. Chemistry of Materials. 2006 Aug 8;18(16):3808-12.

[47] Berl E, Schmidt A, Koch H. The development of carbon. Angewandte Chemie. 1932;45:0517-9.

[48] Corma A, Iborra S, Velty A. Chemical Routes for the Transformation of Biomass into Chemicals. Chemical Reviews. 2007;107(6):2411-502.

[49] Seah MP. Practical Surface Analysis. In: Briggs D, Seah MP, eds.: J. Wiley \& Sons 1990:543.

[50] Moulder JF, Stickle WF, Sobol PE, Bomben KD. Handbook of X-Ray Photoelectron Spectroscopy. In: Chastain J, ed.: Perkin Elemer Corp., Eden Prairie, MN, 1992.

[51] Shirley DA. High-Resolution X-Ray Photoemission Specrum of Valence ands of Gold. Physical Review B. 1972;5(12):4709-\&.

[52] X-ray Photoelectron Spectroscopy Database 20, Version 3.0, National Institute of Standards and Technology, Gaithersburg, MD, [cited; Available from: http://srdata.nist.gov/XPS. ]

[53] Makowski P, Cakan RD, Antonietti M, Goettmann F, Titirici MM. Selective partial hydrogenation of hydroxy aromatic derivatives with palladium nanoparticles supported on hydrophilic carbon. Chemical Communications. 2008(8):999-1001. 
[54] Hu YS, Demir-Cakan R, Titirici MM, Muller JO, Schlogl R, Antonietti M, et al. Superior storage performance of a $\mathrm{Si@SiOx/C} \mathrm{nanocomposite} \mathrm{as} \mathrm{anode} \mathrm{material} \mathrm{for}$ lithium-ion batteries. Angewandte Chemie-International Edition. 2008;47(9):1645-9.

[55] Demir-Cakan R, Hu YS, Antonietti M, Maier J, Titirici MM. Facile one-pot synthesis of mesoporous $\mathrm{SnO} 2$ microspheres via nanoparticles assembly and lithium storage properties. Chemistry of Materials. 2008 Feb 26;20(4):1227-9.

[56] Demir-Cakan R, Baccile N, Antonietti M, Titirici MM. Carboxylate-Rich Carbonaceous Materials via One-Step Hydrothermal Carbonization of Glucose in the Presence of Acrylic Acid. Chemistry of Materials. 2009 Feb 10;21(3):484-90.

[57] Titirici MM, Antonietti M. Chemistry and materials options of sustainable carbon materials made by hydrothermal carbonization. Chemical Society Reviews. 2010;39(1):103-16.

[58] Baccile N, Antonietti M, Titirici MM. One-Step Hydrothermal Synthesis of Nitrogen-Doped Nanocarbons: Albumine Directing the Carbonization of Glucose. ChemSusChem. 2009. DOI:10.1001/cssc.200900124.

[59] Chen J, Wang M, Ho C-T. Volatile Compounds Generated from Thermal Degradation of N-Acetylglucosamine. Journal of Agricultural and Food Chemistry. 1998 07/03/;46(8):3207-9.

[60] Shu C-K. Degradation Products Formed from Glucosamine in Water. Journal of Agricultural and Food Chemistry. 1998 02/12/;46(3):1129-31. 
[61] Jun M, Shao YY, Ho C-T, Koetter U, Lech S. Structural Identification of Nonvolatile Dimerization Products of Glucosamine by Gas Chromatographyâ^’Mass Spectrometry, Liquid Chromatographyâ^’Mass Spectrometry, and Nuclear Magnetic Resonance Analysis. Journal of Agricultural and Food Chemistry. 2003 09/06/;51(21):6340-6.

[62] Baccile N, Laurent G, Babonneau F, Fayon F, Titirici MM, Antonietti M. Structural Characterization of Hydrothermal Carbon Spheres by Advanced Solid-State MAS C-13 NMR Investigations. Journal of Physical Chemistry C. 2009 Jun 4;113(22):9644-54.

[63] Levy GC, Lichter RL, eds. Nitrogen-15 nuclear Magnetic Resonance Spectroscopy. New Your: Wiley 1979.

[64] Gammon WJ, Hoatson GL, Holloway BC, Vold RL, Reilly AC. Bonding in hard and elastic amorphous carbon nitride films investigated using N-15, C-13, and H-1 NMR spectroscopy. Physical Review B. 2003;68(19):195401-1-8.

[65] Sain B, Chaudhuri A, Borgohain JN, Baruah BP, Ghose JL. FURFURAL AND FURFURAL-BASED INDUSTRIAL-CHEMICALS. Journal of Scientific \& Industrial Research. 1982;41(7):431-8.

[66] Ulbricht RJ, Northup SJ, Thomas JA. A REVIEW OF 5HYDROXYMETHYLFURFURAL (HMF) IN PARENTERAL SOLUTIONS. Fundamental and Applied Toxicology. 1984;4(5):843-53. 
[67] Antal MJ, Mok WSL, Richards GN. KINETIC-STUDIES OF THE REACTIONS

OF KETOSES AND ALDOSES IN WATER AT HIGH-TEMPERATURE .1. MECHANISM OF FORMATION OF 5-(HYDROXYMETHYL)-2-FURALDEHYDE FROM D-FRUCTOSE AND SUCROSE. Carbohydrate Research. 1990;199(1):91-109.

[68] Asghari FS, Yoshida H. Acid-Catalyzed Production of 5-Hydroxymethyl Furfural from d-Fructose in Subcritical Water. Industrial \& Engineering Chemistry Research. 2006 02/23/;45(7):2163-73.

[69] Lourvanij K, Rorrer GL. Dehydration of Glucose to Organic-Acids in Microporous Pillared Clay Catalysts. Applied Catalysis a-General. 1994 Feb 17;109(1):147-65.

[70] Harrison TJ, Dake GR. Expeditious, high-yielding construction of the food aroma compounds 6-acetyl-1,2,3,4-tetrahydropyridine and 2-acetyl-1-pyrroline. Journal of Organic Chemistry. 2005;70(26):10872-4.

[71] Bravo A, Herrera JC, Scherer E, Ju-Nam Y, Rubsam H, Madrid J, et al. Formation of alpha-dicarbonyl compounds in beer during storage of Pilsner. Journal of Agricultural and Food Chemistry. 2008;56(11):4134-44.

[72] Liu Y, Gaskell KJ, Cheng ZH, Yu LL, Payne GF. Chitosan-coated electrodes for bimodal sensing: Selective post-electrode film reaction for spectroelectrochemical analysis. Langmuir. 2008;24(14):7223-31. 
[73] Pietrzak R, Wachowska H, Nowicki P. Preparation of nitrogen-enriched activated carbons from brown coal. Energy \& Fuels. 2006 May;20(3):1275-80.

[74] Sevilla M, Fuertes AB. Chemical and Structural Properties of Carbonaceous Products Obtained by Hydrothermal Carbonization of Saccharides. Chemistry - A European Journal. 2009;15(16):4195-203.

[75] Lahaye J, Nanse G, Bagreev A, Strelko V. Porous structure and surface chemistry of nitrogen containing carbons from polymers. Carbon. 1999;37(4):585-90. 


\title{
Supplementary data
}

\section{Sustainable Nitrogen-Doped Carbonaceous Materials from Biomass Derivatives}

\author{
Li Zhao $^{[1,2,5]}$, Niki Baccile ${ }^{[3]}$, Silvia Gross ${ }^{[4]}$, Yuanjian Zhang ${ }^{[1]}$, WeiWei ${ }^{[2]}$, Yuhan \\ Sun $^{[2]}$, Markus Antonietti ${ }^{[1]}$, and Maria-Magdalena Titirici ${ }^{*}[1]$
}

1. Max-Planck Institute for Colloids and Interfaces, Am Mühlenberg 1, 14476 Potsdam-Golm, Germany.

2. Institute of Coal Chemistry, Chinese Academy of Sciences, 030001 Taiyuan, China

3. Laboratoire de Chimie de la Matière Condensée de Paris, CNRS Collège de France, 11 Place Marcelin Berthelot, 75005 Paris, France

4. ISTM-CNR, Dipartimento di Scienze Chimiche and INSTM, University of Padova, Via Marzolo 1, 35131 Padova, Italy

5. Graduate University of the Chinese Academy of Sciences, 100039 Beijing, China

* Corresponding Author. Maria-Magdalena Titirici $\quad$ Fax: (+) 49 (0)331 5679502 ,

E-mail: magdalena.titirici@mpikg.mpg.de, 

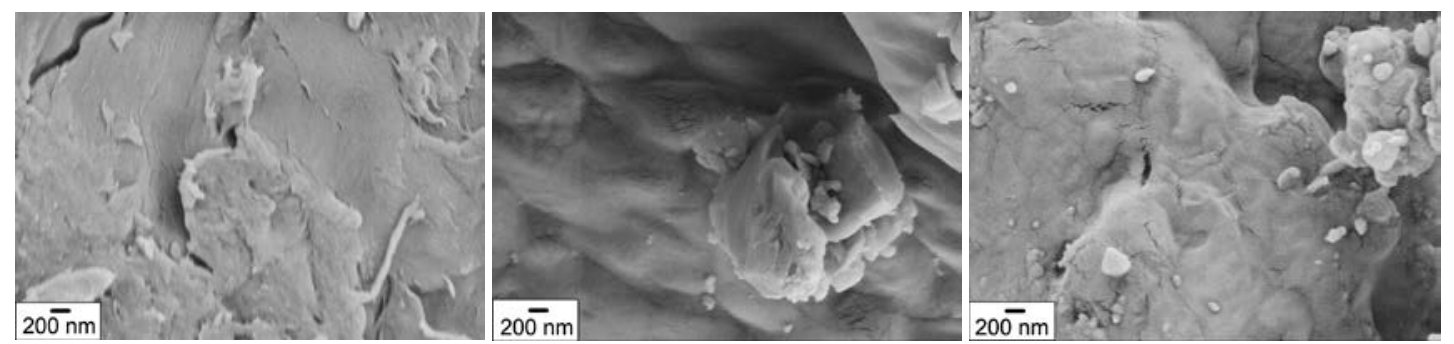

Fig. S 1 - Scanning electron micrographs of the pure precursors of. a) chitosan; b) glucosamine; c) glucose
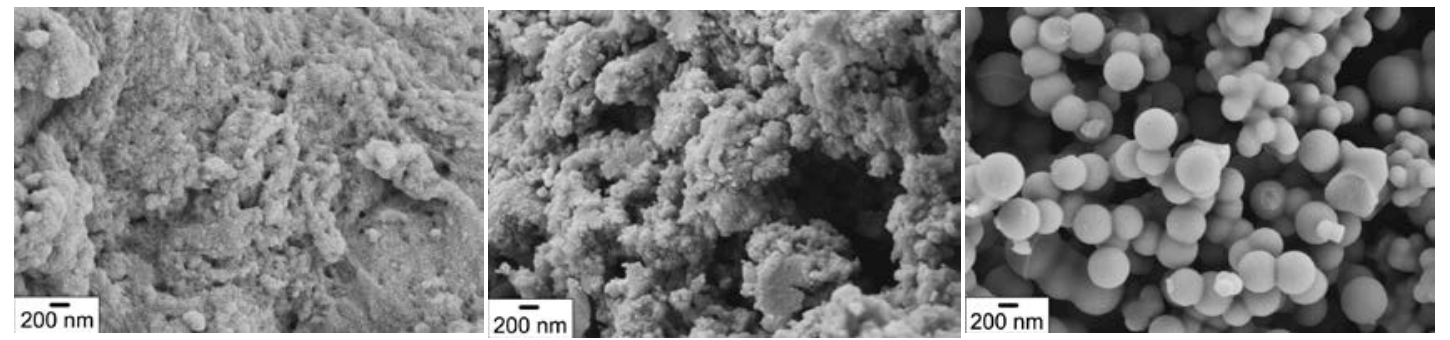

Fig. S 2 - Scanning electron micrographs of the nitrogen doped carbons obtained upon high temperature treatment of a) chitosan (HC-CH-750); b) glucosamine (HC-GA-750) c) glucose (HC-G-750) 

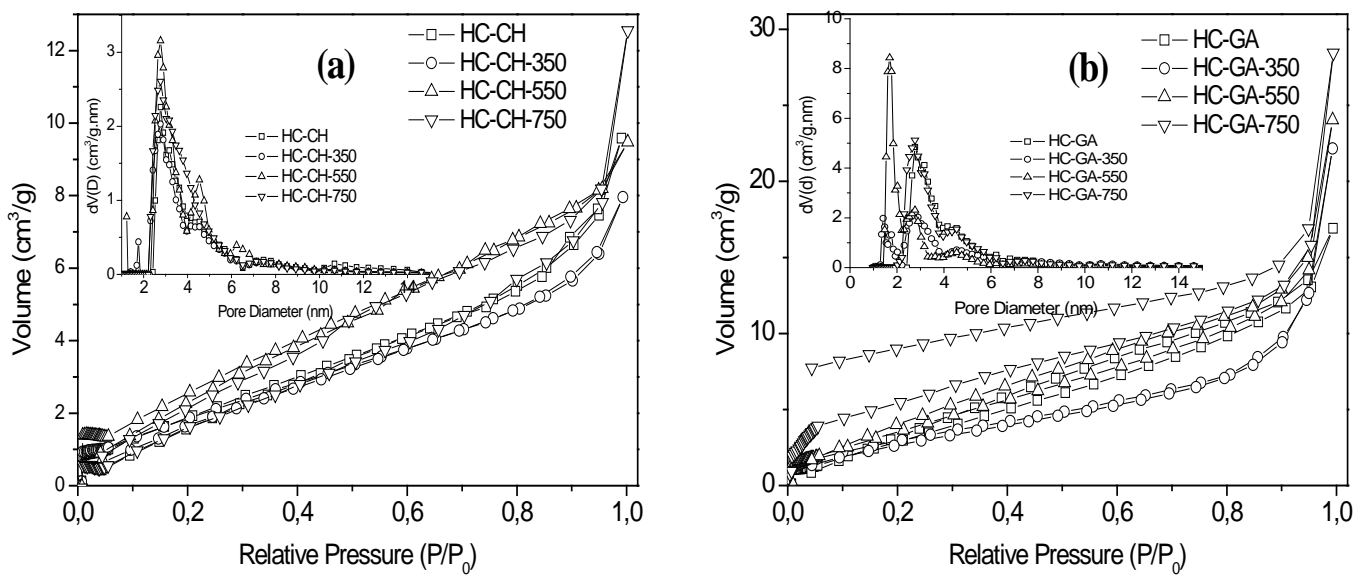

Fig. $\mathrm{S} 3-\mathrm{N}_{2}$ adsorption-desorption isotherms and DFT pore size distributions of carbons obtained after HTC $180^{\circ} \mathrm{C}$ from (a) Chitosan and (b) Glucosamine 

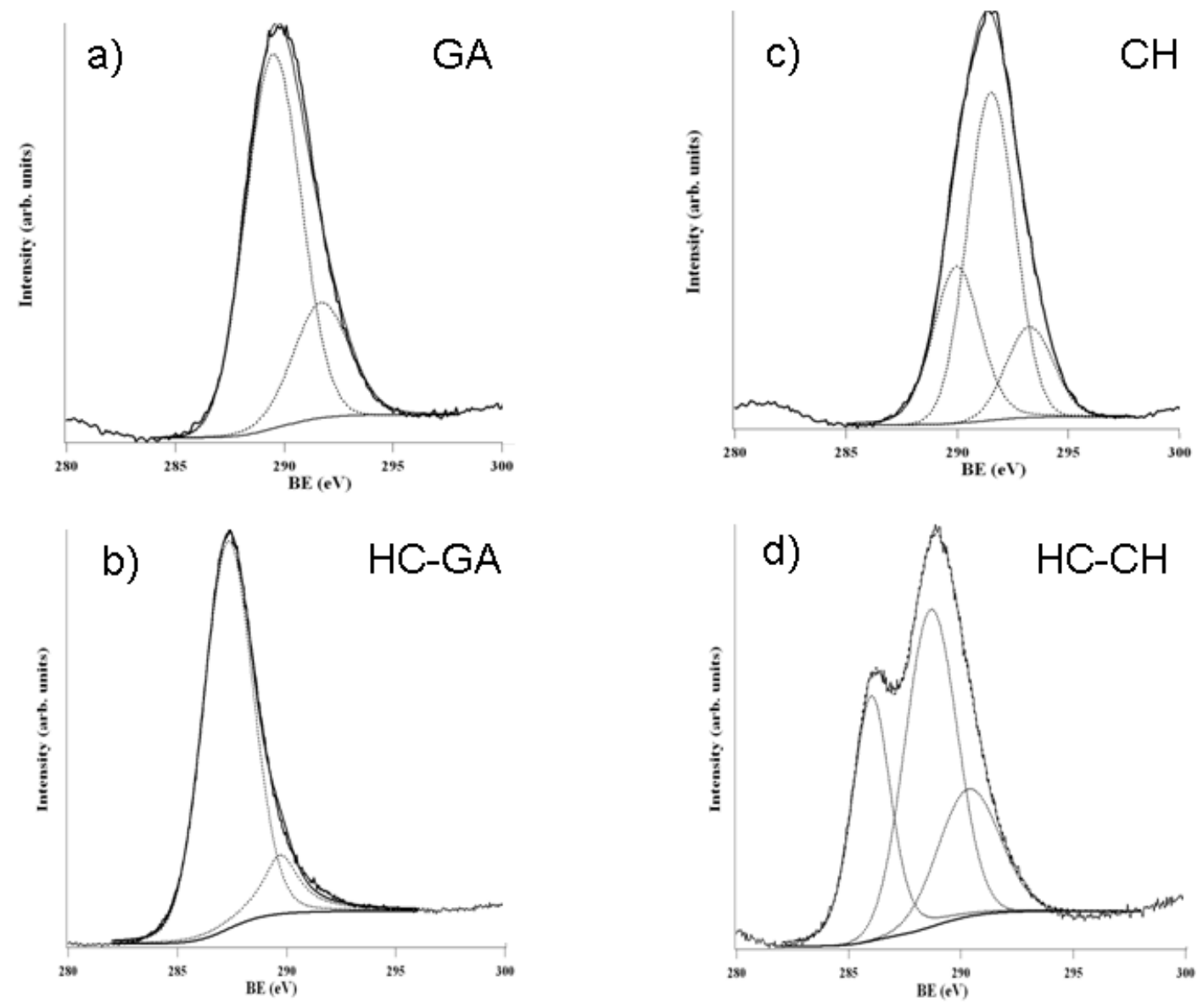

Fig. S 4 - C1s signals of the pure and hydrothermally treated glucosamine (GA) and chitosan $(\mathrm{CH})$ samples. The values in the abscissa are not corrected for the charging effects. Refer to discussion in the text or to

Table $\mathbf{S} \mathbf{1}$ for corrected values. 
Table S 1 - Binding energies values for the pure, hydrothermally treated and calcined glucosamine (GA) and chitosan (CH) samples. These values have been corrected for the charging effects.

\begin{tabular}{|c|c|c|c|}
\hline Sample & Region & $\begin{array}{r}\text { Binding } \\
\text { energy }(\mathrm{eV})\end{array}$ & Assignment \\
\hline \multirow[t]{4}{*}{ Pure Glucosamine } & C1s & 286.1 & $\mathrm{C}-\mathrm{OH}$ \\
\hline & C1s & 288.3 & $\mathrm{C}-\mathrm{O}-\mathrm{C}$ \\
\hline & N1s & 400.0 & $\mathrm{~N}-\mathrm{H}_{2}$ \\
\hline & N1s & 402.0 & $\begin{array}{c}\mathrm{Na}^{+} \mathrm{Cl} \text { (reported value } \\
401.5 \text { ) }\end{array}$ \\
\hline \multirow[t]{4}{*}{ Pure Chitosan } & C1s & 284.6 & $\mathrm{sp}^{3} \mathrm{C}-\mathrm{H}$ \\
\hline & C1s & 286.1 & C-OH, C-OR, \\
\hline & C1s & 287.9 & C-O-C \\
\hline & N1s & 399.3 & $\mathrm{~N}-\mathrm{H}_{2}$ \\
\hline \multirow[t]{4}{*}{ HC-GA } & C1s & 286.1 & $\mathrm{C}-\mathrm{OH}$ \\
\hline & C1s & 288.3 & C-O-C \\
\hline & N1s & 400.0 & $\mathrm{~N}-\mathrm{H}_{2}$ \\
\hline & N1s & 402.0 & Oxidized N \\
\hline \multirow[t]{4}{*}{$\mathrm{HC}-\mathrm{CH}$} & C1s & 284.6 & $\mathrm{sp}^{3} \mathrm{C}-\mathrm{H}$, aromatic carbon \\
\hline & C1s & 287.3 & $\mathrm{C}=\mathrm{O}$ \\
\hline & C1s & 288.9 & $\mathrm{O}-\mathrm{C}=\mathrm{O}$ or \\
\hline & N1s & 402.1 & Oxidized N \\
\hline
\end{tabular}




\begin{tabular}{|l|c|c|l|}
\hline HC-GA-750 & C1s & 285.0 & \\
\hline & N1s & 398.1 & \\
\hline & N1s & 400.8 & \\
\hline HC-CH-750 & C1s & 285.1 & \\
\hline & N1s & 398.1 & \\
\hline & N1s & 400.7 & \\
\hline
\end{tabular}

